\title{
The surgical treatment of traumatic rupture of aortic valve and atrial septum after blunt chest trauma: literature review and presentation of a rare case
}

Tratamento cirúrgico de ruptura traumática da valva aórtica e do septo interatrial, após traumatismo fechado do tórax: revisão da literatura e apresentação de um caso raro

Mauro Barbosa ARRUDA FILHO, Heraldo MAIA E SILVA, Flávia Arruda de Godoy SANTOS, Sérgio da Costa RAYOL, Ana Paola Morais ARRUDA, Cláudia Arruda Buarque de GUSMÃO, Ednaldo FONTES JUNIOR, Mauro Barbosa ARRUDA

RBCCV 44205-635

Abstract: The case of a 49-year-old man who suffered a car accident responsible for several chest injuries including fractures of the left ribs, large subcutaneous emphysema and left hemopneumothorax arrived in shock in the Emergency Room of the Real Hospital Português de Beneficência in Pernambuco (RHPBPE). He was hospitalized for 30 days including some time in the intensive care unit and but did not show signs of diastolic murmur or heart failure. He was submitted to an echocardiography examination that diagnosed slight aortic incompetence, good left ventricular function and was discharged after clinical improvement. Three months later he started to feel symptoms of heart failure and returned to cardiac Emergency Room of the same Hospital. He repeated transthoracic and transesophageal echocardiography examinations presenting severe aortic incompetence due to leaflet disruption, rupture of atrial septum with enlargement of the right cardiac chambers and poor left ventricular function. He underwent surgical treatment of these lesions, with direct approach of the atrial septum and the aortic valve was replaced with a mechanical prosthesis, with a good result.

Descriptors: Heart injuries. Wounds and injuries, heart. Aortic valve, surgery. Heart septum, surgery.

Resumo

Paciente do sexo masculino, 49 anos, atendido $n$ a Emergência do Real Hospital Português de Beneficência (RHPBPE), após acidente automobilístico, apresentando dispnéia, fraturas de múltiplos arcos costais, enfisema subcutâneo extenso e hidropneumotórax à esquerda e fratura da clavícula direita. Submetido inicialmente à drenagem torácica subaquática à esquerda e traqueostomia, tendo sido mantido em respiração controlada no respirador de volume na Unidade de Terapia Intensiva. Recebeu alta após um mês da admissão com ecocardiograma transtorácico que mostrava insuficiência aórtica e insuficiência mitral leve, com leve

Work performed in the Cardiovascular and Thoracic Surgery Department and Realcor Cardiology Emergency of the Real Heart Hospital, Pernambuco, Recife, PE, Brazil.

Correspondence address: Mauro B. Arruda Filho. Rua Gervásio Fioravante, 87/202, Graças, Recife, PE CEP: 52011-030. E-mail: arrudamf@hotlink.com.br 
aumento das câmaras cardíacas esquerdas, com função global preservada, não se relacionando os achados ao trauma. Após três meses, retornou à Emergência cardiológica do mesmo Hospital com sinais e sintomas de insuficiência cardíaca congestiva. Submetido a ecocardiograma transtorácico e transesofágico que mostraram insuficiência aórtica grave e septo interatrial pérvio. À exploração cirúrgica encontramos a desinserção da cúspide não coronariana e ruptura do septo interatrial. A tentativa de reinserir a cúspide não permitiu

\section{INTRODUCTION}

Cardiac lesions resulting from blunt thoracic trauma are uncommon but very important due to the high morbidmortality rate.

The most common cardiac lesion after blunt traumas of the thorax is myocardial contusion which is infrequently diagnosed [1]. Lesions of septa [2], of the free wall of the ventricles and of the coronary vessels are rare and generally, diagnosed at necropsy [3].

Rupture of the aortic valve is, however, a very rare condition [4], specifically when associated with a rupture of the interatrial septum, with only two cases published in world literature $[5,6]$. The diagnosis generally is delayed, as these patients suffer from multiple thoracic lesions and present with hemodynamic instability diverting the attention away from the valvar lesion, which in the majority of cases is diagnosed at a later time with the appearance of signs and symptoms.

In this work we present the case of dis-insertion of the non-coronary cuspid and the rupture of the interatrial septum in a victim of blunt thoracic trauma in a car accident, who was successfully submitted to surgery.

\section{CASEREPORT}

A 49-year-old male patient was attended on the $2 \mathrm{nd}$ January 2001 in the emergency department of the Real Hospital Português de Beneficência in Pernambuco (RHPBPE), after a car accident. At admittance the patient was conscious with dyspnea and cyanosis of the extremities. The pulses were weak, heart rhythm regular, heart beat of 109 beats per minute, arterial pressure $100 \times 60 \mathrm{mmHg}$ and no murmurs were auscultated. Pulmonary auscultation evidenced the vesicular murmur was suppressed to the left, observing an extensive subcutaneous emphysema also on the left. The abdomen did not present with alterations. A uma coaptação completa da valva aórtica, optando-se por sua substituição com implante de uma prótese metálica St. Jude número 23. A ruptura do septo interatrial foi corrigida por aproximação direta com pontos separados. $O$ paciente recebeu alta no $9^{\circ}$ dia de pós-operatório, sem intercorrências e assintomático.

Descritores: Traumatismos cardíacos. Ferimentos e lesões, coração. Valva aórtica, cirurgia. Septo cardíaco, cirurgia. thoracic radiography demonstrated the presence of fractures in multiple left costal arches (3rd, 4th, 5th and 6th), fracture of the right clavicle and hemopneumothorax on the left. The patient was submitted to closed thoracic drainage from the left and tracheostomy, maintaining controlled respiration with a volume respirator, in the intensive care unit.

He evolved with hemodynamic instability, and required vasoactive drugs. There are no reports of the appearance of murmurs. The patient was submitted to thoracic computerized tomography as he presented with widening of the mediastinum, which did not confirm vascular lesions. On the 15th day of hospital a bedside transthoracic echocardiogram was performed, which verified: a slight increase in the left heart chambers with preserved global systolic function, a small degree of aortic incompetence and slight mitral incompetence. The following measurements were made: final diastolic diameter $(\mathrm{FDD})=58$, final systolic diameter $(\mathrm{FSD})=40$, left atrium $(\mathrm{LA})=43$, final diastolic volume $(\mathrm{FDV})=167$, final systolic volume $(\mathrm{FSV})=118$, ejection fraction $(\mathrm{EF})=0.58 \%$, shortening percentage $(\Delta \%)$ $=31 \%$.

At the time the aortic incompetence was not associated with the trauma and after a clinical improvement, the patient was released from the intensive care unit and later from hospital. In May of the same year, because of signs and symptoms of heart failure, the patient returned to the heart unit of RHPBPE. A Thoracic echocardiogram was made confirming: severe aortic incompetence, moderate mitral incompetence, an increase in the left heart chambers, mainly of the left ventricle and serious compromise in the left ventricle function. An important increase of the right heart chambers not seen in the previous examination was also evidenced. In order to identify the mechanism of the aortic regurgitation, the patient underwent a transoesophageal echocardiogram, which showed dis-insertion of the noncoronary cuspid with aortic incompetence and the presence of interatrial communication not diagnosed by the 
transthoracic echocardiogram (Figures 1, 2, 3 and 4). With the diagnosis of the aortic cuspid rupture and of the interatrial septum the patient was referred to our department.

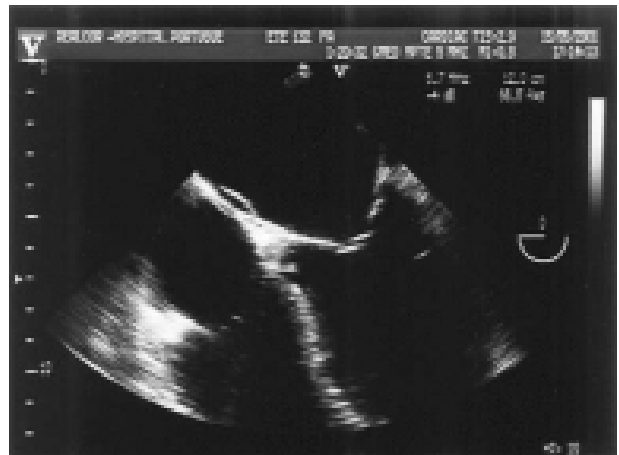

Fig. 1-Aspect of the transoesophageal echocardiogram performed three months after trauma

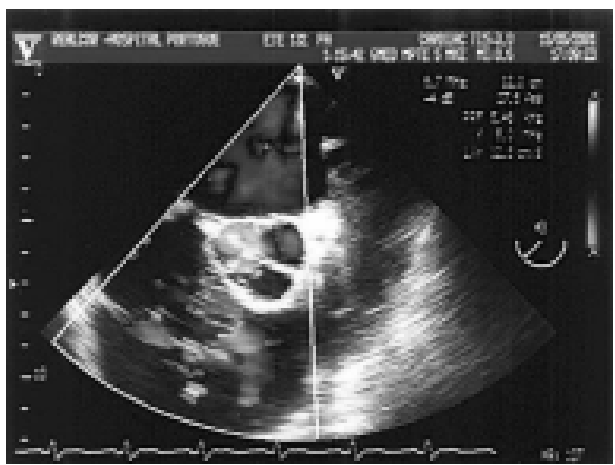

Fig. 2-Aspect of the transoesophageal echocardiogram showing aortic failure

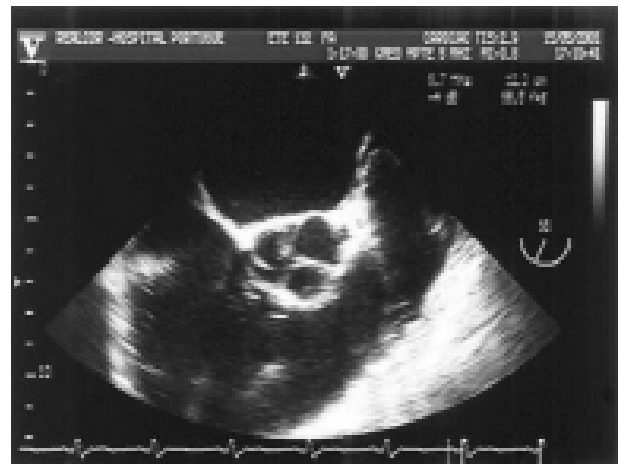

Fig. 3-Aspect of the transoesophageal echocardiogram, showing rupture of the non-coronary aortic cuspid

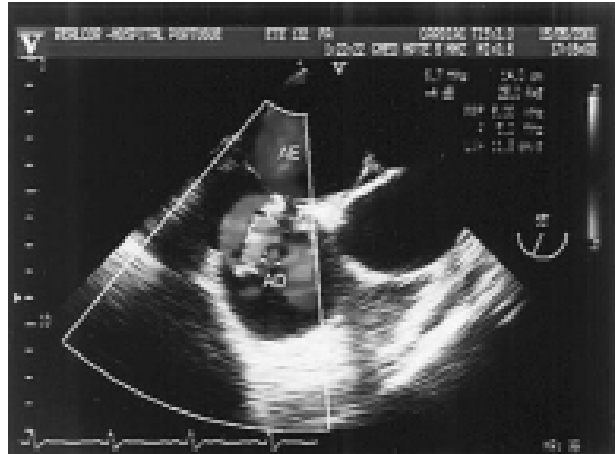

Fig. 4-Transoesophageal echocardiogram showing the interatrial septum rupture

On the 23rd May 2001 the patient was submitted to surgical treatment utilizing median sternotomy, cardiopulmonary bypass at normothermia, with catheterization of the ascending aorta and both the vena cavas. Myocardial protection was achieved with normothermia anterograde sanguineous cardioplegia repeated at every twenty minutes. After aortotomy, the almost complete dis-insertion of the non-coronary cuspid of the aortic annulus was visualized (Figure 5).

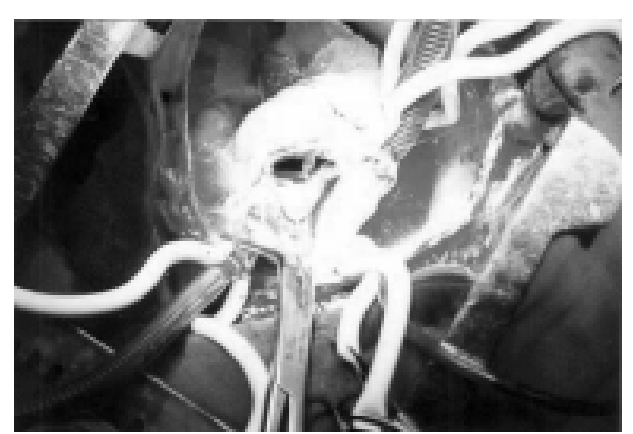

Fig. 5 - Surgical aspect of the non-coronary cuspid rupture

A reinsertion was attempted using continuous sutures, which did not provide a complete coaptation of the aortic valve, and its substitution with a St. Jude number 23 metallic prosthesis was chosen. At right atriotomy a rupture of the interatrial septum was visualized (Figure 6), at the oval foramen. An atrioseptoplasty from the right using separate sutures was performed. After normalization of the temperature, removal of air from the left cavities, unclamping of the aorta and regularization of the heartbeats, the cardiopulmonary bypass was interrupted and the arterial 


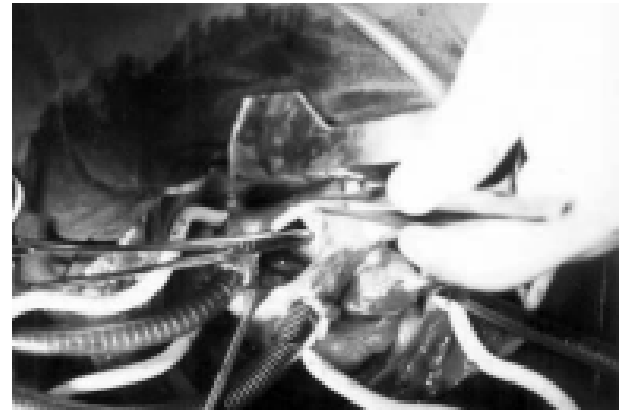

Fig. 6-Surgical aspect of the rupture of the interatrial septum

and venous catheters removed. The patient had event free trans- and post-operative periods and was released from hospital on the 9th post-operative day.

Control echocardiograms demonstrated progressive regression of the heart dimensions with an improved systolic performance presenting with the following measurements: on $25 / 06 / 02-\mathrm{DDF}=52, \mathrm{DSF}=39, \mathrm{AE}=40, \mathrm{VDF}=141, \mathrm{VSF}$ $=59, \mathrm{FE}=049, \Delta \%=25$, and on $10 / 07 / 02-\mathrm{DDF}=49, \mathrm{DSF}=$ $35, \mathrm{AE}=42, \mathrm{VDF}=118, \mathrm{VSF}=35, \mathrm{FE}=0,55, \Delta \%=29$.

\section{COMMENTS}

Several heart structures can be affected originating from blunt thoracic trauma, however the occurrence of aortic valvar failure associated to rupture of the interatrial septum is very rare with only two published cases in the international literature. The first case was described by MACKINTOSH AND FLEMING [5], in 1992 and the second reported by TSAI et al. [6] in 1999.

The most frequent site of lesions is the region of the isthmus, at the arterial ligament where the most mobile section of the descending aorta joins to the most fixed portion of the aortic arch. This region is responsible for the greatest incidence of ruptures (15 to $20 \%$ ) and deaths in victims of car accidents [7].

Aortic failure is rarer in an analysis of publications and works performed in autopsies, and it is believed that it occurs due to the sudden increase of intrathoracic pressure during diastole, when the pressure gradient through the valve is at its maximum, and the valve is closed [8].

The incidence of traumatic rupture of the interatrial septum is even rarer and its mechanism is still not totally understood, but the diagnosis is generally made late and can occur several years after the accident [9].

In the majority of the cases acute aortic failure provokes a rapid deterioration of the patient's clinical state, presenting signs of heart failure. In some cases the diagnosis is also made later by the disguise that the multiple traumatic patient presents. In this case, as a diastolic murmur does not appear in the initial phase, it does not arouse any early suspicions.
The transthoracic echocardiogram is the most-used noninvasive diagnostic method in heart lesions, with transoesophageal echocardiogram being used when the clinical condition of the patient allows. This is more specifically used to visualize the mechanism of the lesion, the valvar anatomy, the myocardial function and the presence of associated lesions such as interatrial communication [10,11]. Initial hemodynamic instability, as well as, the lack of the appearance of the murmur did not prompt the performing of a transoesophageal echocardiogram. The transthoracic echocardiogram performed on the 15th day of hospitalization in the intensive care unit only showed slight aortic incompetence, so the patient was released from hospital after a clinical improvement.

With the appearance of dyspnea and signs of congestive heart failure three months after the accident the transthoracic echocardiogram was repeated which compared to the previous examination demonstrated severe aortic incompetence, moderate mitral incompetence, an increase in the left and right heart chambers and left ventricle dysfunction. A transoesophageal echocardiogram was indicated which showed the dis-insertion of the noncoronary cuspid, as well as interatrial septum rupture (Figures 4 and 5). The patient was submitted to coronary cineangiography to exclude coronary artery lesions and referred to surgical treatment. The surgical indication should be made as fast as possible, after establishing the diagnosis, to avoid greater damage to the myocardium.

Despite of some reports of aortic valvar plastia in cases of post-trauma rupture [12], it was not possible due to the shortening of the coronary cuspid which did not allow an adequate coaptation of the valve. The atrioseptoplasty was performed using an approach from the right as it was not very expanse.

The rarity of the post-trauma association of aortic valve failure and interatrial communication with later development to heart failure, with this being the first Brazilian case described and the third international case, makes this report of special interest.

\section{BIBLIOGRAPHIC REFERENCES}

1. Westaby S, Brayley N. ABC of major trauma: thoracic trauma BMJ 1990; 300:1639-43.

2. Moraes CR, Victor E, Arruda M, Cavalcanti I, Raposo L, Lagreca JR et al. Ventricular septal defect following nonpenetrating trauma: case report and review of the surgical literature. Angiology 1973; 24: 222-9.

3. Parmley L, Manion W, Mattingly T. Nonpenetrating traumatic injury of the heart. Circulation 1958; 18: 371-96. 
4. Unal M, Demirsoy E, Gogus A, Arbatli H, Hamzaoglu A Sonmez B. Acute aortic valve regurgitation secondary to blunt chest trauma. Tex Heart Inst J 2001; 28: 312-4.

5. Mackintosh AF, Fleming HA. Cardiac damage presenting late after road accidents. Thorax 1981;36:811-3.

6. Tsai FC, Hsieh JR, Lee CC, Hui YL, Lin PJ, Chang CH. Posttraumatic aortic valve regurgitation and atrial septum rupture. J Trauma 1999; 47: 591-3.

7. Sturm JT, McGee MB, Luxenberg MG. An analysis of risk factors for death at the scene following traumatic aortic rupture. J Trauma 1988; 28:1578-80.

8. Munshi IA, Barie PS, Hawes AS, Lang SJ, Fischer E. Diagnosis and management of acute aortic valvular disruption secondary to rapid deceleration trauma. J Trauma 1996; 41:1047-50.
9. Banning AP, Durrani A, Pillai R. Rupture of the atrial septum and tricuspid valve after blunt chest trauma. Ann Thorac Surg 1997; 64: 240-2.

10. Ussia GP, Rapezzi C, Ferlito M, Piovaccari G, Magnani B. Valvular lesions in the course of nonpenetrating thoracic trauma: their diagnosis by transesophageal echocardiography. Cardiologia 1996; 41: 1107-11.

11. Brandstatt P, Carlioz R, Fontaine B, Hemery Y, Pats B, Chapuis $O$ et al. Acute post-traumatic aortic insufficiency: transesophageal echocardiography in the diagnosis and therapy of the lesions. Ann Cardiol Angeiol 1998; 47: 563-7.

12. Halstead J, Hosseinpour AR, Wells FC. Conservative surgical treatment of valvular injury after blunt chest trauma. Ann Thorac Surg 2000; 69:766-8. 